\title{
Density, viscosity, surface tension, and excess properties of DSO and gas condensate mixtures
}

\author{
Ahmad Khorami ${ }^{1} \cdot$ Seyed Ali Jafari ${ }^{1} \cdot$ Mohamad Mohamadi-Baghmolaei $^{1} \cdot$ \\ Reza Azin ${ }^{2}$ (D) Shahriar Osfouri ${ }^{1}$
}

Received: 11 July 2017/ Accepted: 2 October 2017/Published online: 23 October 2017

(C) The Author(s) 2017. This article is an open access publication

\begin{abstract}
Disulfide oil (DSO) mostly burned or stored is known as a low-grade byproduct in gas refining industries. This material is highly perilous to environment. A common way to reduce the environmental impact of DSO is blending in a specific ratio with gas condensate stream in gas refinery. This would improve DSO quality and consequently strengthen its unique application. In this work, density, viscosity and surface tension of DSO and gas condensate mixtures were measured and modeled. Viscosity and density of DSO, gas condensate, and their mixtures were measured in temperature range of 283.15-318.15 K. In addition, surface tension was measured at $298.15 \mathrm{~K}$ at different volumetric fractions of DSO-gas condensate mixture. Excess molar volume $\left(V^{\mathrm{E}}\right)$, viscosity deviation $(\Delta \mu)$, deviation of excess Gibbs free energy $\left(\Delta G^{\mathrm{E}}\right)$, and excess surface tension $\left(\sigma^{\mathrm{E}}\right)$ were determined based on measured properties. Results showed a positive and negative trend for excess molar volume and excess surface tension, respectively. While fluctuation was observed in viscosity deviation and deviation of excess Gibbs free energy and results showed positive and negative values in different mole fraction. In addition, RedlichKister equation is proposed to predict excess properties of DSO and gas condensate mixtures.
\end{abstract}

Reza Azin

reza.azin@pgu.ac.ir

1 Chemical Engineering Department, Faculty of Petroleum, Gas and Petrochemical Engineering, Persian Gulf University, Bushehr 7516913798, Iran

2 Petroleum Engineering Department, Faculty of Petroleum, Gas and Petrochemical Engineering, Persian Gulf University, Bushehr 7516913798, Iran
Keywords DSO - Gas condensate - Excess property · Viscosity $\cdot$ Gibbs free energy $\cdot$ Surface tension

\section{List of symbols}

A Parameters of the Redlich-Kister equation

$G \quad$ Gibbs energy $\left(\mathrm{J} \mathrm{mol}^{-1}\right)$

$M \quad$ Molecular weight $\left(\mathrm{kg} \mathrm{mol}^{-1}\right)$

$n$ Number of parameters used in the Redlich-Kister equation

$N \quad$ Number of experimental data

$P \quad$ Desired property

$R \quad$ Gas constant $\left(\mathrm{J} \mathrm{mol}^{-1} \mathrm{~K}^{-1}\right)$

$T$ Temperature (K)

$V$ Molar volume $\left(\mathrm{m}^{3} \mathrm{~mol}^{-1}\right)$

$x$ Mole fraction

$w$ Mass fraction

Greek characters

$\gamma$ Surface tension $\left(\mathrm{mN} \mathrm{m}^{-1}\right)$

$\Delta$ Deviation of each property

$\mu \quad$ Viscosity ( $\mathrm{mPa} \mathrm{s})$

$\rho$ Density $\left(\mathrm{kg} \mathrm{m}^{-3}\right)$

$\sigma$ Surface tension $\left(\mathrm{mN} \mathrm{m}^{-1}\right)$

\section{Subscripts}

E Excess property

\section{Superscripts}

1 Gas condensate

2 DSO

i Integer number

exp Experimental

pred Predicted 


\section{Introduction}

Disulfide oil (DSO) is a byproduct of demercaptanization unit from LPG by Merox process [1]. During this process, mercaptan (R-SH) is converted to mercaptide salt (R$\mathrm{S}^{-} \mathrm{Na}^{+}$) in a reaction with $\mathrm{NaOH}$, as shown in Eq. (1). It is then converted to disulfide in the presence of catalysts and in combination with oxygen, as shown in Eq. (2) [2]. Schematic of Merox process is shown in Fig. 1 [3]:

$\mathrm{RSH}+\mathrm{NaOH} \rightarrow \mathrm{NaSR}+\mathrm{H}_{2} \mathrm{O}$

$4 \mathrm{NaSR}+\mathrm{O}_{2}+2 \mathrm{H}_{2} \mathrm{O} \stackrel{\text { Cat. }}{\rightarrow} 2 \mathrm{RSSR}+4 \mathrm{NaOH}$.

DSO is a chemical mixture with general chemical formula as RSSR', in which two alkyl groups have been connected to a sulfur-sulfur connective link $[4,5]$. These chemicals are usually a combination of dimethyl disulfide (DMDS), diethyl disulfide (DEDS), and methyl ethyl disulfide [6]. Table 1 presents typical composition of a DSO stream in a Fajr Jam gas refining complex (FJGRC) located in Bushehr province, around $60 \mathrm{~km}$ away from northern Persian Gulf coastline, Iran.

This is highly flammable at room temperature with yellowish color and unpleasant odor like garlic. Adverse effects of DSO on humans, animals, plants, and aquatic culture have identified it as a hazardous material. It is a potential source of cancer, threatens fertility, and also may cause skin irritation and inflammation [6,7]. There is not any common practical application for DSO so far. It is known as a low-grade byproduct that usually stored or burned once production [8]. Its storage would make a serious problem as any leakage into water and soil will cause irreparable consequences. Burning DSO, on the other hand, emits toxic gases such as $\mathrm{H}_{2} \mathrm{~S}, \mathrm{CO}, \mathrm{CO}_{2}$, and carbonyl compounds [6]. Regarding to statistics announced by gas refineries, considerable portion of emitted greenhouse gases (GHG) belongs to incinerators. Therefore, according to the world commitment legislation for GHG reduction, any effort in case of decreasing environmental pollutants or changing their user would be of paramount importance.

Some applications are proposed for disulfide component during recent years, e.g., removal of asphaltene and solid sulfur compounds from oil wells $[5,9]$ and production of cyclic compounds such as thiophene [10-12]. In some literature, adding DSO to hydrocarbon cutoff such as gas condensate in gas refineries presented as an alternative which not only eliminates the DSO burning and storage problems but also improves its economic aspect [13]. However, this would restrict the usage of such mixture as on-road diesel fuel due to the worldwide sulfur content limitations. Since, environmental regulations in Europe in 2009 have forced petroleum industries to reduce their sulfur contents to $10 \mathrm{ppm}$ [8].

It should be taking into account that the main purpose of mixing DSO and condensate is increase in DSO price. Adding gas condensate to DSO may facilitate its exportation. In addition, as it was mentioned before, this mixture can be utilized as asphaltene solvent in enhanced oil recovery processes. Therefore, knowledge of physical properties such as density, viscosity, surface tension, and
Fig. 1 Schematic of Merox process [3]

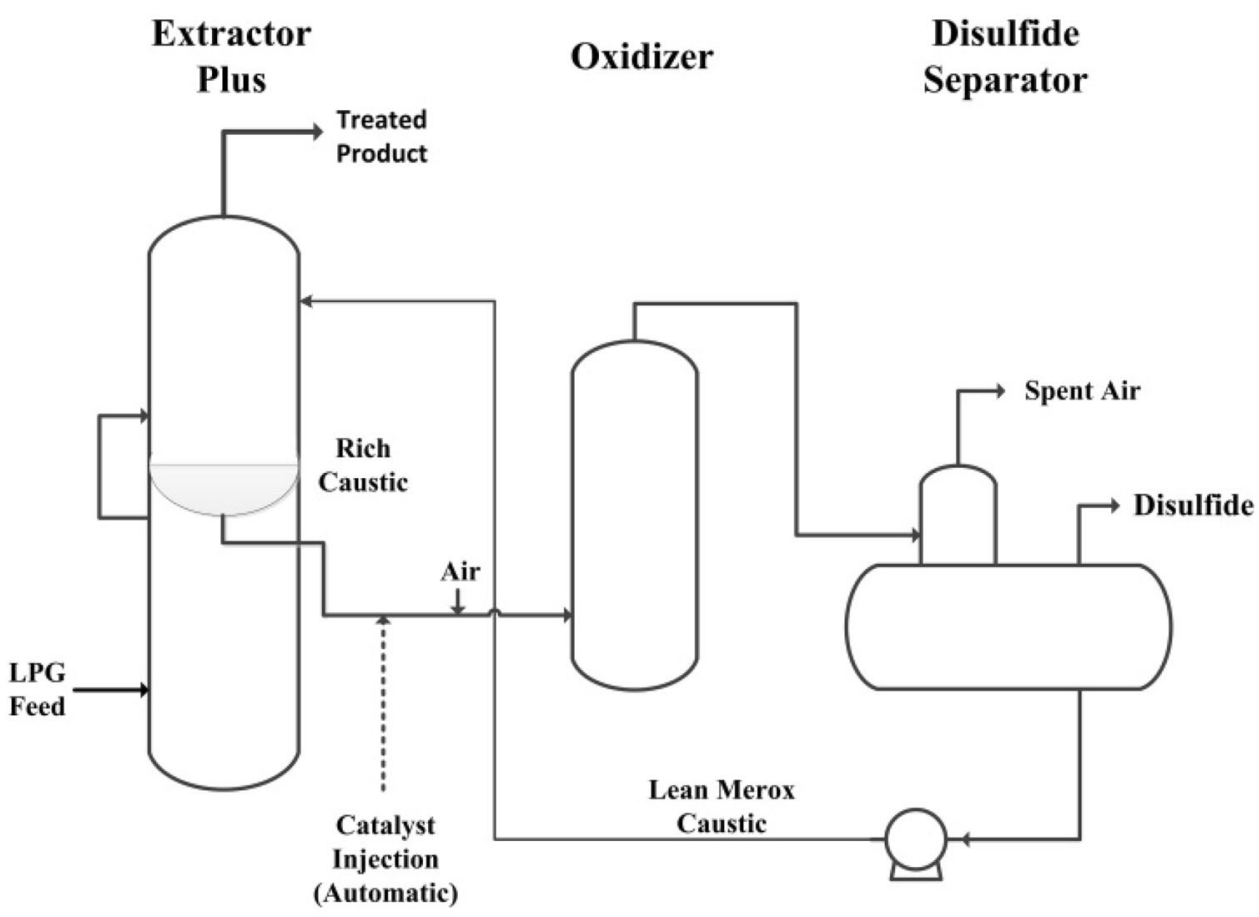


Table 1 DSO composition

\begin{tabular}{ll}
\hline Parameter & Quantity \\
\hline Water content/wt\% & 0.11 \\
Sulfur content/wt\% & 51.2 \\
Metal content/ppm & $<0.09$ \\
Dimethyl disulfide/wt\% & $46-58$ \\
Diethyl disulfide/wt\% & 32 \\
Diethyl sulfide/wt\% & $10-20$ \\
Dipropyl sulfide + methyl propyl disulfide + diisopropyl & $<2$ \\
disulfide/wt\% & \\
\hline
\end{tabular}

Table 2 Properties of DSO and gas condensate samples

\begin{tabular}{lll}
\hline Property & DSO & Gas condensate \\
\hline Freezing point/K & 193 & - \\
Initial boiling point/K & 383.95 & 309 \\
Final boiling point/K & 447.65 & 529 \\
Molecular weight/g mol $^{-1}$ & 94 & 78 \\
Specific gravity at $293.55 \mathrm{~K}$ & 1.0127 & 0.7175 \\
\hline
\end{tabular}

excess molar volume of DSO and gas condensate along with their mixtures can play a vital role in equipment design [14].

Rare literature was found on studying properties of this mixture. Based on searches, the current work would be likely done for the first time. Few studies have focused on measurement physical properties of either DSO or condensate separately; however, more elaboration was focused on modeling of these products. For instance, Dyusengaliev et al. studied on extraction of DMDS, diethyl methyl disulfide, and DEDS from DSO produced in Tengiz Gas Refinery in Kazakhstan [15]. Sokolsky et al. also investigated the structural and chemical characteristics of this byproduct [16]. Dysangaliev et al. reported density, boiling point, refractive index, sulfur content, solubility in different solvents, and geometrical structure of DSO produced in Tengiz Gas Refinery [17]. Taheri et al. focused on biological elimination of DSO from soil using several bacterial strains [6]. Kornetova et al. recently studied on solubility of wax and asphaltene components via DSO as solvent. It was found that DSO was not enough to dissolve these materials except in combination with surfactants and aromatic hydrocarbons [18]. In case of gas condensate, Zhang et al. studied some properties of gas condensate of Karachaganak reservoir, including PVT properties and interfacial tension [19]. Bonyadi and Esmaeilzadeh predicted density of several gas condensates using Esmaeilzadeh-Roshanfekr (ER) and Peng-Robinson (PR) equations of state (EOS) and compared with PVT observations. They found that ER-EOS was more reliable than
PR-EOS to predict density of the studied gas condensate [20]. In addition, Nikookar et al. used DashtizadehPazuki-Taghikhani-Ghotbi (DPTG) EOS for a better prediction of gas condensate density [21].

In this study, density, viscosity, and surface tension of DSO and gas condensate mixtures are measured with different volume fractions and temperature range of 283.15-318.15 K, followed by presenting a mathematical approach to predict these physical properties. In addition, excess properties such as molar volume, viscosity deviations, excess Gibbs free energy, and surface tension are calculated, as well.

\section{Materials and methods}

DSO and gas condensate were provided from Fajr Jam gas refinery company, Bushehr, Iran. Physical properties of these products as well as gas condensate constituents are given in Tables 2 and 3, respectively.

Mixtures of DSO and gas condensate were prepared in a range of $0-100 \% \mathrm{v} / \mathrm{v}$ with $10 \%$ steps using volumetric glass flasks (Simax, Germany, $\pm 0.06 \mathrm{ml}$ uncertainty) and micropipette (Brand, Germany, $\pm 0.001 \mathrm{ml}$ accuracy) at room temperature and atmospheric pressure. The taken volume of each sample is checked gravimetrically according to their initial densities by an AND balance with $\pm 10^{-4} \mathrm{~g}$ resolution (GR-300). The mixtures were miscible in all volumetric ratios. However, to assure well mixing, blending is performed using a magnetic stirrer for almost $1 \mathrm{~min}$. All measurements were conducted immediately after sample preparation to avoid any disturbance in volume ratio and composition upon vaporization.

Viscometer SVM3000 (Anton Paar) were utilized to measure density, and kinetic and dynamic viscosities of DSO and gas condensate mixtures according to ASTM D7042 [22] with the precision of $\pm 10^{-4} \mathrm{~g} \mathrm{~cm}^{-3}$ and $\pm 10^{-5} \mathrm{mPa} \mathrm{s}$, respectively. The main part of device includes two nested cylinders; the internal one rotates mechanically at $4000 \mathrm{rpm}$. Maximum $5 \mathrm{ml}$ of sample is required to conduct the measurement. A small syringe is used to inject the samples into viscometer. Each sample is analyzed at atmospheric pressure and temperatures range of 283.15-318.15 K with 5-degree steps. Temperature adjustment is performed by controlling device screen. The viscometer automatically performs tests in triplicates and results that are shown finally are the average values.

Surface tension of mixtures was measured by a digital tensiometer (TD1C, Lauda) with Du Noüy ring method according to ASTM D1331-14 [23], which measures contact surface of liquid mixture with gas phase (air) at room temperature and atmospheric pressure with the precision of $\pm 0.01 \mathrm{mN} \mathrm{m}^{-1}$. The device is calibrated using double- 
Table 3 Gas condensate components of Fajr jam gas refining complex (FJGRC)

\begin{tabular}{|c|c|c|}
\hline & Components & wt $\%$ \\
\hline 1. & Propane & 0.13 \\
\hline 2. & Isobutane & 1.97 \\
\hline 3. & $N$-butane & 4.54 \\
\hline 4. & Isopentane & 7 \\
\hline 5. & $N$-pentane & 6.34 \\
\hline 6. & 2,2-Dimethylbutane (CA1) & 0.92 \\
\hline 7. & 2-Methylpentane (CA2) & 6.68 \\
\hline 8. & 3-Methylpentane (CA3) & 3.19 \\
\hline 9. & $N$-hexane & 5.88 \\
\hline 10. & 2,4-Dimethylpentane (CA4) & 2.93 \\
\hline 11. & Benzene & 2.68 \\
\hline 12. & Cyclohexane & 2.3 \\
\hline 13. & 2,3-Dimethylpentane (CA5) & 3.88 \\
\hline 14. & 3-Methylhexane (CA6) & 2.85 \\
\hline 15. & 2,2,4-Trimethylpentane (CA7) & 1.04 \\
\hline 16. & $N$-heptane & 3.07 \\
\hline 17. & Methylcyclohexane (CA8) & 4.2 \\
\hline 18. & 2,5-Dimethylhexane (CA9) & 0.35 \\
\hline 19. & Toluene & 5.06 \\
\hline 20. & 2,3,4-Trimethylpentane (CA10) & 1.85 \\
\hline 21. & 3-Methylheptane (CA11) & 1.4 \\
\hline 22. & $N$-octane & 3.04 \\
\hline 23. & 1-Trans-2-Dimethylcyclohexane (CA12) & 0.43 \\
\hline 24. & 2,2-Dime-3-ethylpentane (CA13) & 0.47 \\
\hline 25. & Ethylcyclohexane (CA14) & 0.73 \\
\hline 26. & Ethylbenzene (CA15) & 0.44 \\
\hline 27. & P,M-Xylene (CA16) & 5.53 \\
\hline 28. & $N$-nonane & 3.24 \\
\hline 29. & $N$-propylbenzene (CA17) & 2.04 \\
\hline 30. & 1,2,4-Tri-methylbenzene (CA18) & 1.95 \\
\hline 31. & Mesitylene (CA19) & 0.8 \\
\hline 32. & $N$-decane & 2.41 \\
\hline 33. & UnDecane (CA20) & 3.97 \\
\hline 34. & DoDecane (CA21) & 2.12 \\
\hline 35. & TriDecane(CA22) & 1.57 \\
\hline 36. & Tetradecane (CA23) & 1.16 \\
\hline 37. & Pentadecane (CA24) & 0.74 \\
\hline 38. & $\mathrm{C} 16+$ & 1.1 \\
\hline
\end{tabular}

distilled water and extra pure methanol. After pouring sample into cup of the device, the ring is sunk into liquid followed by swiping it up gently. As the ring is coming out of liquid sample, the device records increasing force exerted to ring by surface of sample. The maximum force recorded is exactly where the junction between ring and sample is broken and known as surface tension. Due to handheld nature of the device, tests are conducted

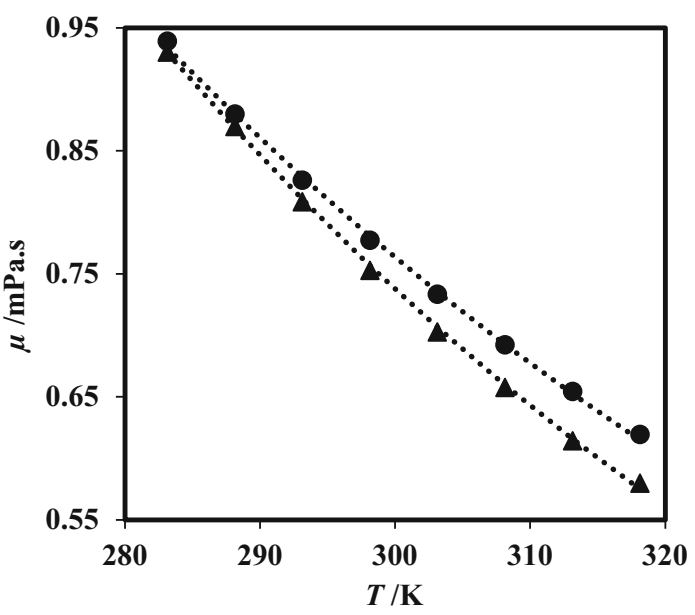

Fig. 2 Viscosity $\mu$ of gas condensate and DSO as a function of temperature $T$. Measured viscosities: solid triangle, gas condensate; solid circle, DSO and dotted line, and correlated viscosities

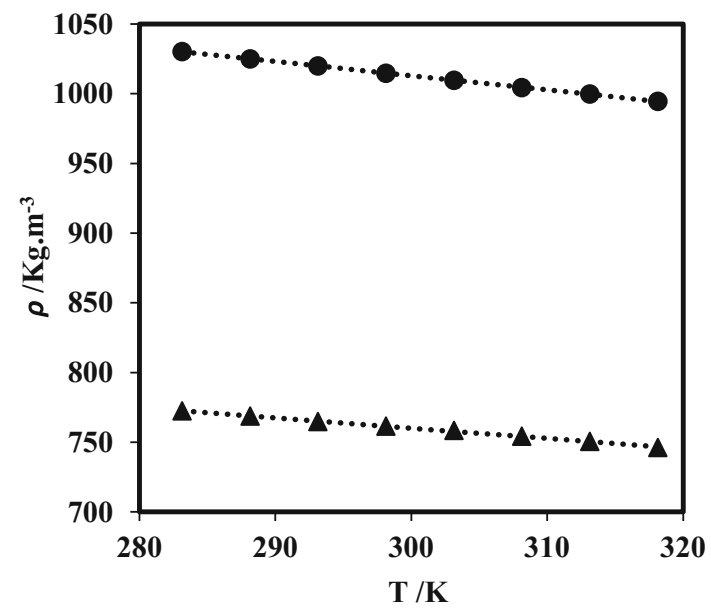

Fig. 3 Density $\rho$ of gas condensate and DSO as a function of temperature $T$. Measured densities: solid triangle, gas condensate; solid circle, DSO and dotted line, and correlated densities

manually in duplicates and confidence intervals (CI) of 95\% determine for each sample.

\section{Results and discussion}

\section{Density and viscosity of DSO and gas condensate}

Figures 2, 3 shows measured density and viscosity of DSO and gas condensate before mixing, respectively. These pure properties are used for predicting properties of mixture.

An empirical exponential-type equation as Eq. (3) was proposed to predict viscosity of gas condensate and DSO versus temperatures. The general form of correlation of viscosity versus temperature has been proposed in the 
Table 4 Constants of viscosity and density equations for gas condensate and DSO

\begin{tabular}{lllll}
\hline Compound & \multicolumn{4}{l}{ Constant } \\
\cline { 2 - 5 } & $a_{1}$ & $a_{2}$ & $a_{3}$ & $a_{4}$ \\
\hline Gas condensate & 45.49 & -0.01374 & -0.7383 & 981.6 \\
DSO & 27.52 & -0.01195 & -1.017 & 1318 \\
\hline
\end{tabular}

literature [24], while the coefficients were optimized. The coefficients in the following equations were achieved using nonlinear optimization technique and least square method in MATLAB programming software (2010A) with the aim of achieving maximum $\mathrm{R}$-square:

$\mu=a_{1} \exp \left(a_{2} T\right)$

where $\mu$ is viscosity in $\mathrm{mPa}$ s and $T$ is absolute temperature in $\mathrm{K}$. Constants, $\mathrm{a}_{1}$ and $\mathrm{a}_{2}$, are dimensionless and achieved through optimization. Final adjusted parameters of Eq. (3) for DSO and gas condensate are given in Table 4. Predicted viscosities based on Eq. (3) are showed in Fig. 2.

As seen, the measured viscosity decreased by increasing in temperature. The average absolute relative error (AARE) of 0.37 and $0.34 \%$ was obtained for gas condensate and DSO, respectively. The AARE is calculated by the following equation [25]:

$\%$ AARE $=\frac{100}{n} \sum_{i=1}^{N} \frac{\left|P_{\text {pred }}-P_{\exp }\right|}{P_{\exp }}$,

where $P$ is the desired property. Density of gas condensate and DSO was measured at the same temperature range, and Eq. (5) was proposed to predict gas condensate and DSO densities versus temperature. This equation was inspired from a general linear correlation reported by Kariznovi et al. [24]:

$\rho=a_{3} T+a_{4}$,

where $\rho$ is density in $\mathrm{kg} \mathrm{m}^{-3}$. Constants, $a_{3}$ and $a_{4}$ were optimized for each product and shown in Table 4. Measured and predicted densities of gas condensate and DSO at the studied temperatures were showed in Fig. 3.

The AARE values of 0.03 and $0.01 \%$ were obtained for gas condensate and DSO, respectively.

\section{Density, viscosity, and surface tension of gas condensate-DSO mixture}

Density and viscosity of gas condensate and DSO mixtures were measured at different volume fractions and temperatures range of 283.15-318.15 K. Equations (6) and (7) are proposed to predict density and viscosity of mixtures, respectively. The main principle of such correlation

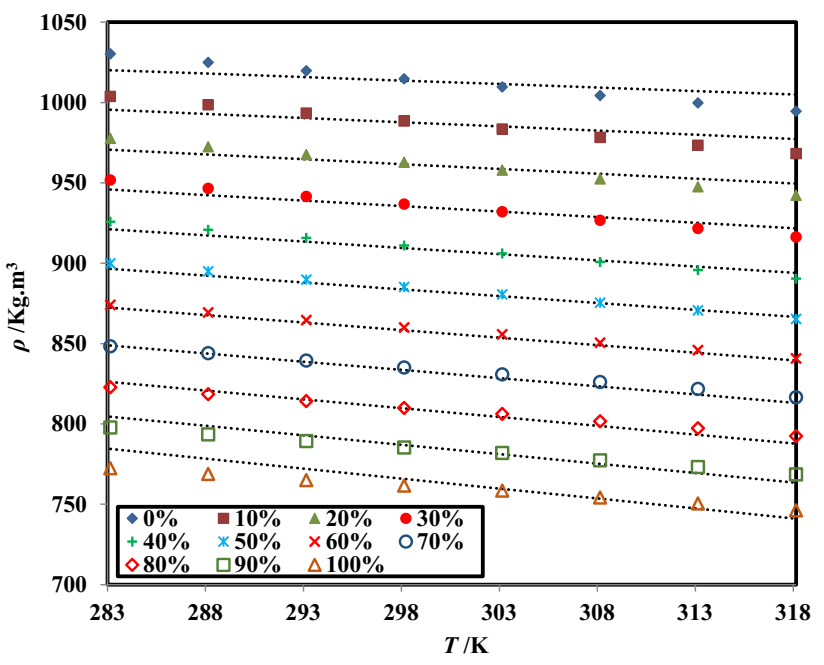

Fig. 4 Gas condensate-DSO mixture density $\rho$ as a function of temperature $T$ at various gas condensate volume fractions. Points show experimental observations and the dotted curve shows the correlation results

development can be found in Mohamadi-Baghmolaei et al. study [26]:

$\rho=0.3153(T+9.299)\left(w_{\text {cond. }}+0.3512\right)\left(w_{\text {cond. }}-3.911\right)$ $+1147$

where $w_{\text {cond. }}$ is gas condensate mass fraction. Results shown in Fig. 4 indicate a good agreement between the experimental and predicted data with AARE of $0.38 \%$. Table 5 also reports the obtained experimental data at the entire range of studied temperatures.

It is clear from Fig. 4 that density of mixture decreased by increasing in gas condensate volume fraction as well as temperature. However, effect of volume fraction on fluid density is much more tangible than temperature. In addition, all density variations versus temperature and volume fractions are linear with high precision. The proposed mathematical model for the prediction of gas condensateDSO mixture viscosity is shown by the following equation:

$\mu=\frac{2.497 \times 10^{7}}{T\left(w_{\text {cond. }}+T\right)\left(4.973 w_{\text {cond. }}+T-9.423\right)}-0.1976$.

The mixture volume fractions and temperatures were the same as those of density. Results are shown in Figs. 5 and 6. In addition, Table 6 shows the obtained experimental viscosities at temperatures between 283.15 and $318.15 \mathrm{~K}$.

In Fig. 5, the predicted viscosities are plotted versus the measured ones. It can be clearly seen that the data deviations at each temperature decreased by increase in temperature, so that the R-squared values at the temperature of 
Table 5 Density $\rho / \mathrm{kg} \mathrm{m}^{-3}$ of gas condensate (1) + DSO (2)

\begin{tabular}{|c|c|c|c|c|c|c|c|c|}
\hline \multirow{2}{*}{$x_{1}$} & \multicolumn{8}{|l|}{$T / \mathrm{K}$} \\
\hline & 283.15 & 288.15 & 293.15 & 298.15 & 303.15 & 308.15 & 313.15 & 318.15 \\
\hline 0 & 1030.2 & 1024.9 & 1019.8 & 1014.7 & 1009.6 & 1004.4 & 999.7 & 994.5 \\
\hline 0.076967 & 1003.7 & 998.5 & 993.4 & 988.4 & 983.5 & 978.2 & 973.4 & 968.1 \\
\hline 0.157978 & 977.6 & 972.5 & 967.5 & 962.9 & 957.9 & 952.5 & 947.6 & 942.3 \\
\hline 0.243358 & 951.7 & 946.6 & 941.5 & 936.8 & 932 & 926.6 & 921.7 & 916.3 \\
\hline 0.333472 & 925.8 & 920.7 & 915.7 & 910.9 & 906.1 & 900.8 & 895.7 & 890.4 \\
\hline 0.428724 & 899.8 & 894.9 & 889.8 & 885.2 & 880.6 & 875.4 & 870.7 & 865.3 \\
\hline 0.529567 & 874.1 & 869.3 & 864.5 & 859.9 & 855.6 & 850.5 & 845.9 & 840.7 \\
\hline 0.636508 & 848.3 & 843.9 & 839.3 & 835 & 830.7 & 826 & 821.7 & 816.5 \\
\hline 0.750117 & 822.8 & 818.5 & 814.1 & 809.9 & 806.1 & 801.5 & 797.2 & 792.4 \\
\hline 0.871038 & 797.7 & 793.4 & 789.3 & 785.2 & 781.8 & 777.2 & 773.1 & 768.5 \\
\hline 1 & 772.4 & 768.8 & 764.9 & 761.5 & 758.4 & 754.2 & 750.5 & 746.2 \\
\hline
\end{tabular}

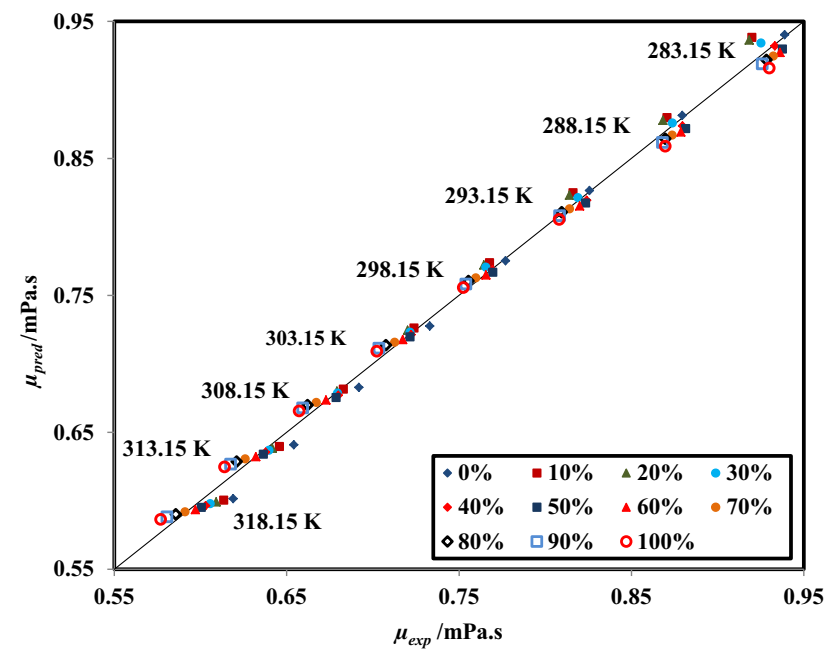

Fig. 5 Residual (experimental versus predicted values) viscosities of gas condensate and DSO mixtures under different gas condensate volume fractions and temperatures

283.15 and $318.15 \mathrm{~K}$ were achieved 0.0105 and 0.9925 , respectively. This phenomenon could be interpreted by weakening of the interaction forces between molecules by increasing temperature [27]. The AARE value for the figure, however, was calculated $0.76 \%$ that is negligible enough to assume accurate correlation. The decreasing trend of mixture viscosity versus temperature is also evident from Fig. 5 and Table 6. The experimental viscosities at the studied temperatures and three gas condensate volume fractions are shown in Fig. 6. As can be seen, the viscosity versus temperature has an exponentially trend for all volume fractions. Although temperature has a significant impact on mixture viscosity, volume fraction has minor effect insofar as the three plotted lines in Fig. 6 are overlapped.

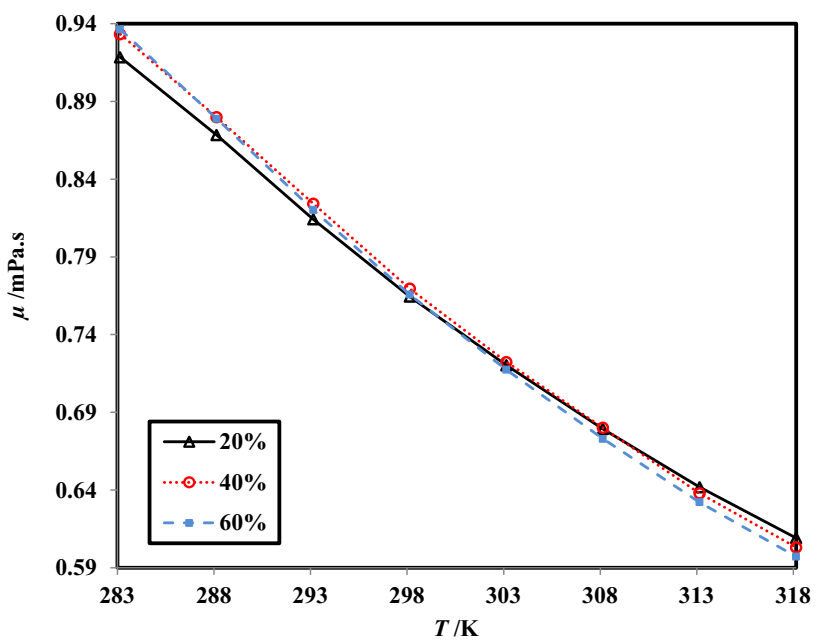

Fig. 6 Experimental viscosities $\mu$ of gas condensate and DSO mixtures at different temperatures $T$

As mentioned, variation of surface tension was measured experimentally at room temperature and atmospheric pressure for the whole range of volume fractions in duplicates. This property was also predicted by Eq. (8) for all mixtures:

$\ln \left(\sigma / \mathrm{mN} \mathrm{m}^{-1}\right)=x_{1} \ln \sigma_{1}+x_{2} \ln \sigma_{2}-0.1984 x_{1} x_{2}$,

where $\sigma$ is surface tension in $\mathrm{mN} \mathrm{m}^{-1}$ and $x$ is mole fraction. The subscripts 1 and 2 in Eq. (8) and the following equations refer to gas condensate and DSO, respectively. Both experimental and predicted surface tensions were plotted in Fig. 7 and the AARE obtained $0.95 \%$.

As can be seen from Fig. 7 and Table 7, surface tension of DSO and gas condensate mixture decreased by increase in gas condensate volume fraction. Experimental data 
Table 6 Viscosity $\mu / \mathrm{mPa} . \mathrm{s}$ of gas condensate (1) + DSO (2)

\begin{tabular}{|c|c|c|c|c|c|c|c|c|}
\hline \multirow[t]{2}{*}{$x_{1}$} & \multicolumn{8}{|l|}{$T / \mathrm{K}$} \\
\hline & 283.15 & 288.15 & 293.15 & 298.15 & 303.15 & 308.15 & 313.15 & 318.15 \\
\hline 0 & 0.93893 & 0.87959 & 0.82577 & 0.77698 & 0.73308 & 0.69204 & 0.6542 & 0.61913 \\
\hline 0.076967 & 0.92001 & 0.87071 & 0.81622 & 0.76785 & 0.72397 & 0.68309 & 0.64594 & 0.61362 \\
\hline 0.157978 & 0.91837 & 0.86827 & 0.81414 & 0.76441 & 0.72021 & 0.67924 & 0.64186 & 0.60918 \\
\hline 0.243358 & 0.9252 & 0.87393 & 0.81915 & 0.76574 & 0.72168 & 0.67962 & 0.63994 & 0.60583 \\
\hline 0.333472 & 0.93323 & 0.87975 & 0.82416 & 0.76947 & 0.72227 & 0.68004 & 0.63789 & 0.60319 \\
\hline 0.428724 & 0.93771 & 0.88158 & 0.82355 & 0.76973 & 0.72174 & 0.67885 & 0.63665 & 0.60065 \\
\hline 0.529567 & 0.93624 & 0.87874 & 0.82011 & 0.76567 & 0.71734 & 0.67292 & 0.63216 & 0.59717 \\
\hline 0.636508 & 0.93246 & 0.87371 & 0.81426 & 0.75992 & 0.71281 & 0.66738 & 0.62612 & 0.59126 \\
\hline 0.750117 & 0.92831 & 0.86966 & 0.80958 & 0.7555 & 0.70764 & 0.66229 & 0.62107 & 0.58587 \\
\hline 0.871038 & 0.92597 & 0.86799 & 0.80838 & 0.7541 & 0.70367 & 0.65935 & 0.61764 & 0.58062 \\
\hline 1 & 0.92995 & 0.86963 & 0.8082 & 0.7526 & 0.70236 & 0.65731 & 0.61406 & 0.57699 \\
\hline
\end{tabular}

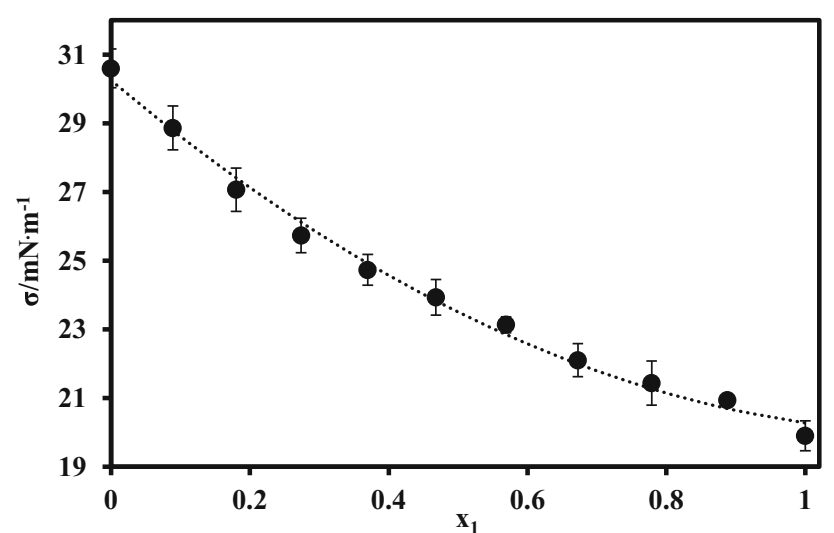

Fig. 7 Experimental and predicted surface tension $\sigma$ at $298.15 \mathrm{~K}$ and different gas condensate mole fractions $x_{1}$

reported in Table 7 were also supplemented by standard deviation values for two replications. The predicted data by Eq. (8) were also listed in Table 7.

\section{Excess properties}

Excess molar volume can be calculated by experimental densities of pure and mixture materials. This property is determined for a binary mixture by the following equation [27-29]:

$V^{\mathrm{E}}=\frac{x_{1} M_{1}+x_{2} M_{2}}{\rho}-\left(\frac{x_{1} M_{1}}{\rho_{1}}+\frac{x_{2} M_{2}}{\rho_{2}}\right)$,

where $V^{\mathrm{E}}$ is excess molar volume in $\mathrm{m}^{3} \mathrm{~mol}^{-1}$ and $M$ is molar mass in $\mathrm{kg} \mathrm{mol}^{-1}$. The Redlich-Kister equation is used to predict the excess molar property of gas condensate-DSO mixture [30]:

$P=x_{1}\left(1-x_{1}\right) \sum_{i=0}^{n} A_{\mathrm{i}}\left(1-x_{1}\right)^{i}$, where $P$ is the desired property and $A$ is a regulator coefficient. The subscript $i$ is an integer number considered three in this study. Figure 8 illustrates graphical trend of excess molar volume $V^{\mathrm{E}}$ in more detail. As can be seen, the excess molar volumes are positive for all molar ranges. This phenomenon is likely arising from the interaction effects occurred by mixing condensate and DSO which results in breaking of chemical bonds and increase the total volume after mixing, leading to excess molar volume greater than zero [28]. While the negative excess molar volume may suggest strong interactions such as hydrogen bond between molecules of a mixture [27], the positive value for excess molar volume was also observed by AlTuwaim et al. for different binary mixtures of $N, N$ dimethylformamide in combination with 1-pentanol, 1-hexanol, and 1-heptanol separately [31]. Moreover, Narendra et al. [32] and Kumari et al. [33] found the same trend for anisaldehyde + cresols and acetic acid + toluene mixtures, respectively. The height of curves of excess molar volume illustrated in Fig. 8 increases by increasing temperature that can be attributed to bond breaking and volume expansion by temperature [27-29, 34-36].

Having viscosity of gas condensate and DSO as well as their mixture, the viscosity deviation can be obtained using Eq. (11) as follows [27, 28, 34, 35]:

$\Delta \mu=\mu-\left(x_{1} \mu_{1}+\left(1-x_{1}\right) \mu_{2}\right)$,

where $\Delta \mu$ is viscosity deviation in $\mathrm{mPa}$ s. Prediction of this property was conducted using Redlich-Kister equation, as well. Figure 9 illustrates the experimental and predicted viscosity deviations at different gas condensate mole fraction and temperatures.

From Fig. 9, it can be observed that viscosity deviations of mixture represent a $\mathrm{W}$-shape trend for all mole fractions and temperatures in which the negative parts appeared at 

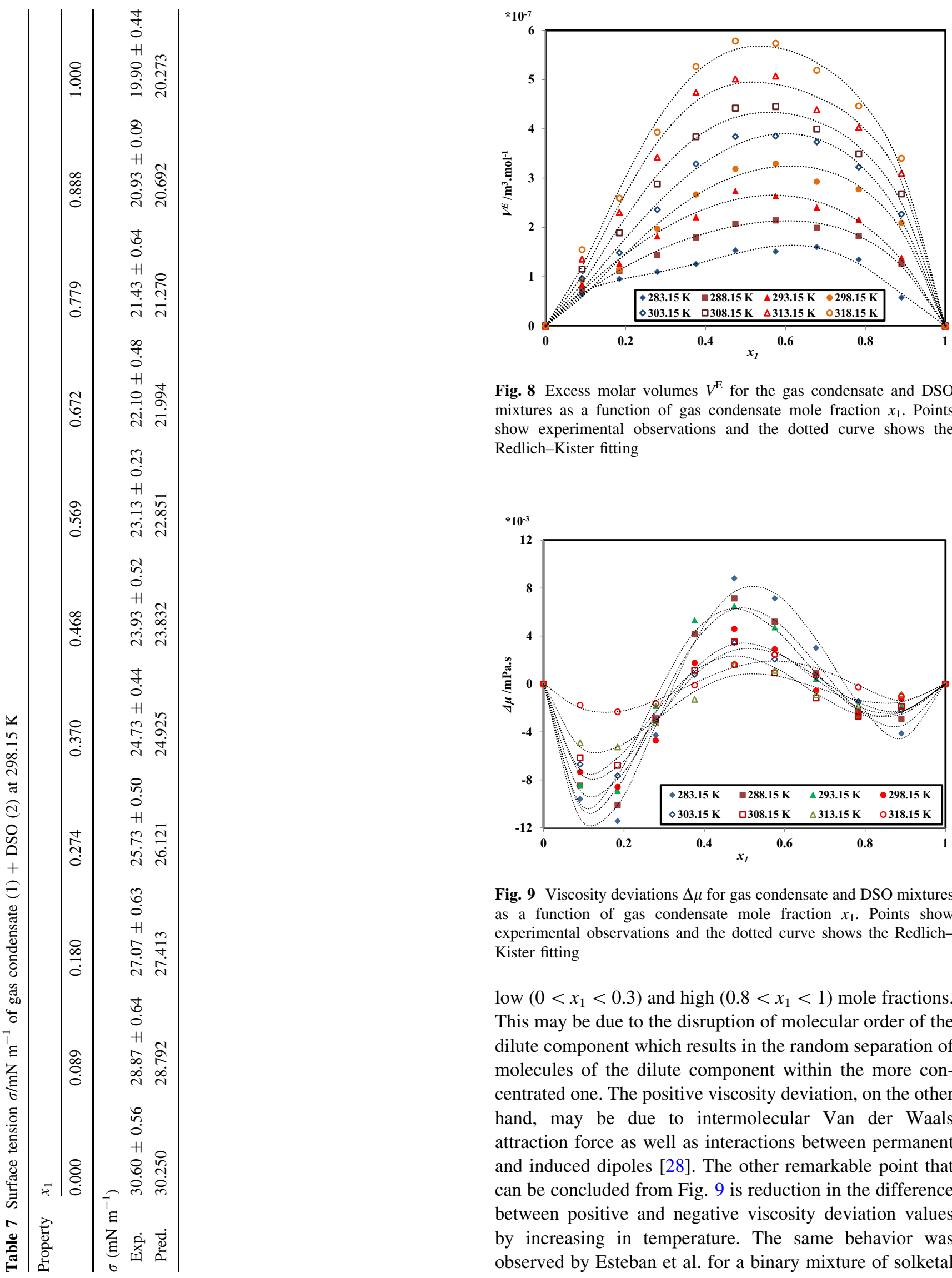

Fig. 8 Excess molar volumes $V^{\mathrm{E}}$ for the gas condensate and DSO mixtures as a function of gas condensate mole fraction $x_{1}$. Points show experimental observations and the dotted curve shows the Redlich-Kister fitting

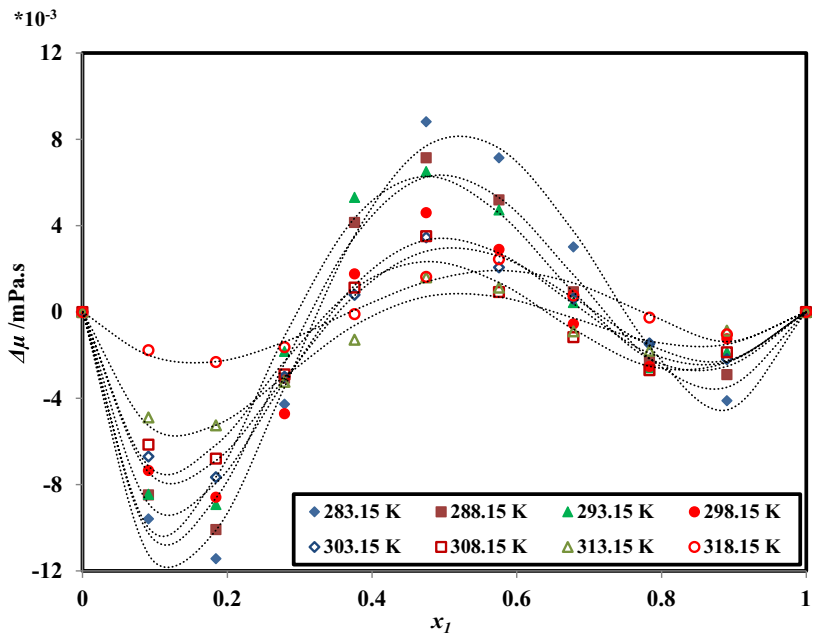

Fig. 9 Viscosity deviations $\Delta \mu$ for gas condensate and DSO mixtures as a function of gas condensate mole fraction $x_{1}$. Points show experimental observations and the dotted curve shows the RedlichKister fitting

low $\left(0<x_{1}<0.3\right)$ and high $\left(0.8<x_{1}<1\right)$ mole fractions. This may be due to the disruption of molecular order of the dilute component which results in the random separation of molecules of the dilute component within the more concentrated one. The positive viscosity deviation, on the other hand, may be due to intermolecular Van der Waals attraction force as well as interactions between permanent and induced dipoles [28]. The other remarkable point that can be concluded from Fig. 9 is reduction in the difference between positive and negative viscosity deviation values by increasing in temperature. The same behavior was observed by Esteban et al. for a binary mixture of solketal 
and $n$-hexadecane [28]. The S-shape behavior was also observed for viscosity deviations in a binary mixture, where a downward peak appeared in early part of the chart and an upward one in late part or vice versa. For instance, similar trends were reported by Kapadi et al. [34] for ethanolamine and water mixture and by and Gómez Marigliano and Solimo [37] for formamide and 1-propanol mixture.

Deviation of excess Gibbs free energy $\left(\Delta G^{\mathrm{E}}\right)$ is considered as another important mixture property and can be determined by Eq. (12) for a binary mixture [28]:

$\Delta G^{\mathrm{E}}=R T\left[\ln (\mu V)-\left(\left(x_{1} \ln \left(\mu_{1} V_{1}\right)+\left(1-x_{1}\right) \ln \left(\mu_{2} V_{2}\right)\right)\right]\right.$,

where $\Delta G^{\mathrm{E}}$ is deviation of excess Gibbs free energy in $\mathrm{J} \mathrm{mol}^{-1}$ and $R$ is gas constant in $\mathrm{J} \mathrm{mol}^{-1} \mathrm{~K}^{-1}$. The molar volume of mixture is also calculated via Eq. (13):

$V=\frac{x_{1} M_{1}+x_{2} M_{2}}{\rho}$.

Deviation of excess Gibbs free energy of mixture calculated by Eq. (12) and predicted data fitted by Redlich-Kister equation is shown in Fig. 10.

It is clear from Fig. 10 that the deviation of excess Gibbs free energy contains both negative and positive parts, forming a W-shape trend. The positive part can be attributed to domination of specific interactions between constituent molecules of mixture, while the negative values imply the dominance of dispersion forces [27, 28, 34]. Esteban et al. found a similar trend for binary mixture of $n$ hexadecane and solketal [28].

Excess surface tension is determined by the following equation [28]:

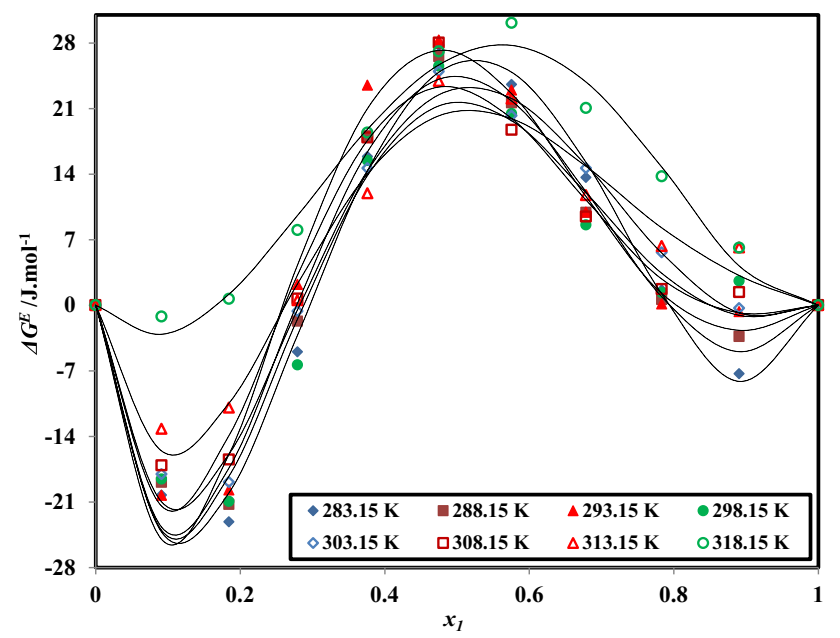

Fig. 10 Deviation of the excess Gibbs free energy $\Delta G^{\mathrm{E}}$ for gas condensate and DSO mixtures as a function of gas condensate mole fraction $x_{1}$. Points show experimental observations and the dotted curve shows the Redlich-Kister fitting
$\sigma^{\mathrm{E}}=\sigma-\left(x_{1} \sigma_{1}+\left(1-x_{1}\right) \sigma_{2}\right)$,

where $\sigma^{\mathrm{E}}$ is excess surface tension in $\mathrm{mN} \mathrm{m}^{-1}$.

The Redlich-Kister equation was also presented to fit the data obtained by Eq. (14). Figure 11 illustrates experimental and predicted excess surface tension.

According to Fig. 11, excess surface tension values are negative in all range of gas condensate mole fractions. It may be assumed that concentration of the component with lower surface tension may be higher at the surface than bulk of liquid mixture [28, 38]. Similar trends were observed by Esteban et al. for a binary mixture consisted of $n$-hexadecane + solketal [28] and Azizian and Hemmati for ethanol + ethylene glycol system [39]. Moreover, Yue and Liu found such a downward dome-shaped graph for several binary systems of $n$-heptane and ethanol as well as 2,2,4-trimethylpentane mixed with ethanol, propanol, 1-pentanol, 1-hexanol, and 1-heptanol [38].

The whole coefficients of Redlich-Kister equation achieved for the prediction properties of excess molar volume, viscosity deviation, deviation of the excess Gibbs free energy, and surface tension for the studied mixture are listed in Table 8.

\section{Conclusion}

In this work, density, viscosity, and surface tension of DSO and gas condensate mixture were measured and modeled by empirical equations. It was found that the AARE\% were less than $1 \%$ for all properties. Furthermore, excess properties such as excess molar volume $\left(V^{\mathrm{E}}\right)$, viscosity deviation $(\Delta \mu)$, deviation of excess Gibb's free energy $\left(\Delta G^{\mathrm{E}}\right)$,

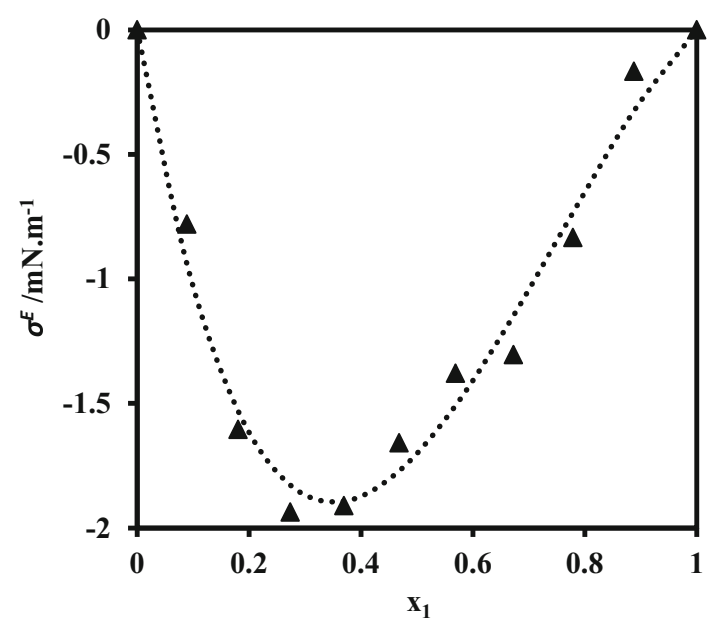

Fig. 11 Excess surface tension $\sigma^{\mathrm{E}}$ for gas condensate and DSO mixtures as a function of gas condensate mole fraction $x_{1}$, at $298.15 \mathrm{~K}$. The solid triangle and dotted line show experimental and Redlich-Kister fitting 
Table 8 Coefficients of the Redlich-Kister equations

\begin{tabular}{|c|c|c|c|c|c|c|c|c|c|}
\hline \multirow[t]{2}{*}{ Property } & \multirow[t]{2}{*}{ Coefficient } & \multicolumn{8}{|l|}{$T / \mathrm{K}$} \\
\hline & & 283.15 & 288.15 & 293.15 & 298.15 & 303.15 & 308.15 & 313.15 & 318.15 \\
\hline \multirow[t]{4}{*}{$V^{\mathrm{E}} / \mathrm{m}^{3} \mathrm{~mol}^{-1}$} & $A_{0} \times 10^{6}$ & 0.46 & 1.46 & 1.52 & 2.43 & 2.59 & 3.21 & 3.93 & 4.1 \\
\hline & $A_{1} \times 10^{6}$ & 2.71 & -2.18 & -1.53 & -4.8 & -3.93 & -7.22 & -10.6 & -9.48 \\
\hline & $A_{2} \times 10^{6}$ & -7.6 & 2.19 & 1.46 & 6.86 & 5.03 & 12.3 & 19.5 & 17 \\
\hline & $A_{3} \times 10^{6}$ & 5.54 & -0.71 & -0.62 & -4.01 & -3.02 & -7.66 & -12.1 & -10.7 \\
\hline \multirow[t]{4}{*}{$\Delta \mu / \mathrm{mPa} \mathrm{s}$} & $A_{0}$ & -0.08683 & -0.05328 & -0.02601 & -0.02908 & -0.03389 & -0.02489 & -0.02015 & -0.03315 \\
\hline & $A_{1}$ & 0.4189 & 0.1534 & -0.0542 & 0.02523 & 0.09721 & -0.0201 & 0.03972 & 0.2182 \\
\hline & $A_{2}$ & -0.1958 & 0.3043 & 0.735 & 0.4011 & 0.1739 & 0.443 & 0.1426 & -0.3428 \\
\hline & $A_{3}$ & -0.3461 & -0.6048 & -0.8598 & -0.5675 & -0.3762 & -0.538 & -0.2578 & 0.1269 \\
\hline \multirow[t]{4}{*}{$\Delta G^{\mathrm{E}} / \mathrm{J} \mathrm{mol}^{-1}$} & $A_{0}$ & -197.3 & -100.4 & -30.88 & -23.41 & -44.67 & -5.379 & 30.02 & -26.14 \\
\hline & $A_{1}$ & 1123 & 378.6 & -176.5 & -21.18 & 274.3 & -206.7 & -71.88 & 752.3 \\
\hline & $A_{2}$ & -664.8 & 863.8 & 2182 & 1440 & 679.7 & 1890 & 1016 & -1133 \\
\hline & $A_{3}$ & -754.7 & -1656 & -2548 & -1914 & -1358 & -2167 & -1321 & 321 \\
\hline \multirow[t]{4}{*}{$\sigma^{\mathrm{E}} / \mathrm{mN} \mathrm{m}^{-1}$} & $A_{0}$ & - & - & - & -1.909 & - & - & - & - \\
\hline & $A_{1}$ & - & - & - & -11.98 & - & - & - & - \\
\hline & $A_{2}$ & - & - & - & 7.976 & - & - & - & - \\
\hline & $A_{3}$ & - & - & - & -7.244 & - & - & - & - \\
\hline
\end{tabular}

and excess surface tension $\left(\sigma^{\mathrm{E}}\right)$ of the studied mixture were determined using experimental data and modeled by Redlich-Kister. It was finally observed that excess molar volume was positive in all range of mixture composition, while both the viscosity and Gibbs free energy deviations unveiled simultaneous positive and negative behavior at different mixture concentration. Negative values were also obtained for excess surface tension in all studied mole fractions.

Acknowledgements The authors acknowledge Fajr Jam Gas Refining Complex for providing gas condensate and DSO products and facilitating site visit, technical documents review, and discussion meetings.

Open Access This article is distributed under the terms of the Creative Commons Attribution 4.0 International License (http:// creativecommons.org/licenses/by/4.0/), which permits unrestricted use, distribution, and reproduction in any medium, provided you give appropriate credit to the original author(s) and the source, provide a link to the Creative Commons license, and indicate if changes were made.

\section{References}

1. Sullivan D (2004) The role of the Merox process in the era of ultra low sulfur transportation fuels. In: 5th EMEA catalyst technology conference

2. US EPA (2010) HPV challenge program data review and assessment for reclaimed substances: disulfides, diethyl and diphenyl, naphtha sweetening. In: American Petroleum Institute

3. UOP Merox ${ }^{\mathrm{TM}}$ LPG treating process. https://www.uop.com/uoplpg-treating-process/. Accessed 1 June 2017
4. Lewand L (2008) Dibenzyl disulfide in transformer oil. In: Doble Engineering Company/NETA World

5. Sharp SP (1983) Method for removal of asphaltene depositions with amine-activated disulfide oil. Patent\# (ed)

6. Taheri HE, Hatamipour M, Emtiazi G, Beheshti M (2008) Bioremediation of DSO contaminated soil. Process Saf Environ Prot 86:208-212

7. Morgott D, Lewis C, Bootman J, Banton M (2014) Disulfide oil hazard assessment using categorical analysis and a mode of action determination. Int J Toxicol 33:181S-198S

8. Kadijani JA, Narimani E (2016) Simulation of hydrodesulfurization unit for natural gas condensate with high sulfur content. Appl Petrochem Res 6:25-34

9. Atkinson FT, Sharp SP, Sudduth LF (1980) Method for dissolving sulfur deposits rapidly. Patent\# (ed)

10. Deryagina E, Korchevin N, Sukhomazova E, Russavskaya N, Levanova YP (1995) Use of disulfide oil in the high-temperature synthesis of heterocyclic compounds. Pet Chem 35:457-462

11. Deryagina E, Sukhomazova E, Levanova E, Korchevin N, Russavskaya N (2004) Thermal reactions of dialkyl disulfides with acetylene in the presence of methanol. Russ J Gen Chem 74:1218-1220

12. Kopylov AY, Sadykov R, Sadikov K, Mazgarov A, Vil'danov A, Ismagilov $\mathrm{Z}$ et al (2008) Catalytic synthesis of thiophene from dialkyl disulfides and $n$-butane. Pet Chem 48:112-117

13. Chretien D (2008) Process and installation for the treatment of DSO. Patent\# (ed)

14. Couper JR, Penney WR, Fair JR (2009) Chemical process equipment revised 2E: selection and design. Gulf Professional Publishing

15. Dyusengaliev K, Serikov T, Kulbatyrov D, Dyusengaliev A, Shakhmanova A, Kuangalyev Z, Kulzhanov D (2011) Problems and prospects of the qualified application «disulfide oils». Chemical Bulletin of Kazakh National University, [S.I.], No. 4, pp 78-81

16. Sokolsky DV (2012) Identification of the components "Disulfide Oil" of Tengizskogo Gpz by physical methods. In: Series of chemistry and technology, vol 1 
17. Dysangaliev K, Saginaev A, Kylbaturov D, Borisov Y, Kh KO (2016) Physicochemical characteristics of the crude 'Disulfide Oil' substitutes. Electron Sci J Oil Gas Bus 2016(5):125-139. doi:10.17122/ogbus-2016-5-125-139

18. Kornetova O, Sharifullin A, Korobkov F, Vil'danov A, Baibekova L (2016) Dialkyl disulfide solvents of asphalt-resin-wax deposits. Chem Technol Fuels Oils 52:612-618

19. Zhang H, Bjørkvik B, Moffatt B (2000) Measurement of flow properties and interfacial tensions for gas condensate systems. In: SPE/CERI gas technology symposium

20. Bonyadi M, Esmaeilzadeh F (2007) Prediction of gas condensate properties by Esmaeilzadeh-Roshanfekr equation of state. Fluid Phase Equilib 260:326-334

21. Nikookar M, Pazuki G, Sahranavard L (2008) Prediction of Gas condensate properties by a new equation of state. In: Canadian international petroleum conference

22. A. International (2004) ASTM D-7042. Standard test method for dynamic viscosity and density of liquids by stabinger viscometer (and the calculation of kinematic viscosity). ASTM International West Conshohocken (ed), PA

23. A. International (2001) ASTM D1331-14. standard test methods for surface and interfacial tension of solutions of paints, solvents, solutions of surface-active agents, and related materials ASTM International West Conshohocken (ed), PA

24. Kariznovi M, Nourozieh H, Guan JG, Abedi J (2013) Measurment and modeling of density and viscosity for mixtures of Athabasca bitumen and heavy $n$-alkane. J Fuel 112:83-95

25. Jafari SA, Jafari D (2015) Simulation of mercury bioremediation from aqueous solutions using artificial neural network, adaptive neuro-fuzzy inference system, and response surface methodology. Desalin Water Treat 55(6):1467-1479

26. Mohamadi-Baghmolaei M, Azin R, Sakhaei Z, MohamadiBaghmolaei R, Osfouri S (2016) Novel method for estimation of gas/oil relative permeabilities. J Mol Liq 223:1185-1191

27. Kapadi U, Hundiwale D, Patil N, Lande M, Patil P (2001) Studies of viscosity and excess molar volume of binary mixtures of propane-1, 2 diol with water at various temperatures. Fluid Phase Equilib 192:63-70

28. Esteban J, Murasiewicz H, Simons TA, Bakalis S, Fryer PJ (2016) Measuring the density, viscosity, surface tension, and refractive index of binary mixtures of cetane with solketal, a novel fuel additive. Energy Fuels 30:7452-7459

29. Fan W, Zhou Q, Sun J, Zhang S (2009) Density, excess molar volume, and viscosity for the methyl methacrylate + 1-butyl-3methylimidazolium hexafluorophosphate ionic liquid binary system at atmospheric pressure. J Chem Eng Data 54:2307-2311
30. Redlich O, Kister A (1948) Algebraic representation of thermodynamic properties and the classification of solutions. Ind Eng Chem 40:345-348

31. AlTuwaim MS, Alkhaldi KH, Al-Jimaz AS, Mohammad AA (2012) Comparative study of physico-chemical properties of binary mixtures of $N, N$-dimethylformamide with 1 -alkanols at different temperatures. J Chem Thermodyn 48:39-47

32. Narendra K, Srinivasu C, Fakruddin S, Narayanamurthy P (2011) Excess parameters of binary mixtures of anisaldehyde with $o$ cresol, $m$-cresol and $p$-cresol at $T=(303.15,308.15,313.15$, and 318.15) K. J Chem Thermodyn 43:1604-1611

33. Kumari A, Sandeepa K, Prathap Kumar T, Satyavathi B (2015) Solubility, thermodynamic properties, and derived excess properties of benzoic acid in (acetic acid + water) and (acetic acid + toluene) binary mixtures. J Chem Eng Data 61:67-77

34. Kapadi U, Hundiwale D, Patil N, Lande M (2002) Viscosities, excess molar volume of binary mixtures of ethanolamine with water at $303.15,308.15,313.15$ and $318.15 \mathrm{~K}$. Fluid Phase Equilib 201:335-341

35. Oswal S, Desai H (2001) Studies of viscosity and excess molar volume of binary mixtures: 3 . 1-alkanol + di- $n$-propylamine, and + di- $n$-butylamine mixtures at 303.15 and $313.15 \mathrm{~K}$. Fluid Phase Equilib 186:81-102

36. Zafarani-Moattar MT, Shekaari H (2006) Application of Prigogine-Flory-Patterson theory to excess molar volume and speed of sound of 1-n-butyl-3-methylimidazolium hexafluorophosphate or 1-n-butyl-3-methylimidazolium tetrafluoroborate in methanol and acetonitrile. J Chem Thermodyn 38:1377-1384

37. Gómez Marigliano AC, Sólimo HN (2002) Density, viscosity, excess molar volume, viscosity deviation, and their correlations for formamide + three alkan-1-ols binary systems. J Chem Eng Data 47:796-800

38. Yue H, Liu Z (2016) Surface tension of binary mixtures of 2, 2 , 4-trimethylpentane + 1-alkanols from 298.15 to $323.15 \mathrm{~K}$. J Chem Eng Data 61:1270-1279

39. Azizian S, Hemmati M (2003) Surface tension of binary mixtures of ethanol + ethylene glycol from 20 to $50{ }^{\circ} \mathrm{C}$. J Chem Eng Data 48:662-663

\section{Publisher's Note}

Springer Nature remains neutral with regard to jurisdictional claims in published maps and institutional affiliations. 